\title{
AVALIAÇÃO DA QUALIDADE DE MAMÕES (CARICA PAPAYA L.)
}

\author{
Polyanna Alves SILVA ${ }^{1 *}$ \\ Juliana Aparecida Candido da Silva ${ }^{1}$ \\ Poliana de Oliveira COELHO ${ }^{2}$ \\ Jessica Machado SILVA ${ }^{3}$ \\ Ellen Leony de Souza ASSUNÇÃO ${ }^{3}$
}

${ }^{1 .}$ Professora Doutora - FACICA, polyalves@gmail.com; julianacandido@ facica.edu.br

2. Professora Mestre, FACICA, poliana@ @acica.edu.br

${ }^{3}$ Graduada em Farmácia Generalista, FACICA, jessica.ms13@hotmail.com; ellen.leony@yahoo.com.br.

*AUTORA PARA CORRESPONDÊNCIA: Dra. Polyanna Alves Silva

Endereço: Rua Simão Martins Ferreira, 64, centro. Campos Gerais, MG. Cep: 37160-000

Email: polyalves@gmail.com

Recebido em: 29/04/2015 - Aprovado em: 02/09/2015 - Disponibilizado em: 30/10/2015

\begin{abstract}
RESUMO
Este trabalho teve como objetivo avaliar a qualidade de 3 grupos de mamões em diferentes estágios de maturação (verde, maduro e de vez) e 3 porções de análises (casca, polpa e sementes). Os frutos foram separados, em 3 lotes (verde, maduro e de vez) com 4 repetições de 3 frutos cada, para a realização das análises físico-químicas das porções casca, polpa e semente. Observou-se que: A acidez total titulável foi maior na polpa e semente do mamão verde e na casca do mamão maduro; Os maiores valores de $\mathrm{pH}$ foram encontrados nas polpas dos mamões maduro e de vez, na semente do mamão de vez e na casca do mamão de vez e verde; Os maiores percentuais de água foram determinados na polpa do mamão verde, nas sementes dos mamões maduro e de vez e na casca do mamão maduro. Os teores de sólidos solúveis totais foram encontrados em maior quantidade na polpa do mamão de vez, nas sementes dos mamões maduro e de vez e na casca do mamão maduro. Com o teste do Biureto as sementes de todos os mamões analisados foram às porções que apresentaram maior concentração de proteínas. O teste de coagulação foi mais eficiente na polpa do mamão verde e nas cascas dos mamões de vez e verde, pois foram as porções que apresentaram o menor tempo de coagulação do leite, demonstrando que as enzimas presentes nestas porções possuem maior capacidade de quebrar as estruturas proteicas.
\end{abstract}

Palavras-chave: Mamão papaia. análises físico-químicas. pós-colheita. segurança alimentar. controle de qualidade.

\section{QUALITY EVALUATION IN PAPAYA (CARICA PAPAYA L.)}

\begin{abstract}
This study aimed to evaluate the quality of 3 groups of papaya at different ripening stages (green, ripe and overripe) considering 3 parts of the fruit (skin, pulp and seed). Fruit were separated into 3 groups (green, ripe and overripe), with 4 replications of 3 fruit each, for physical and chemical analysis of skin, pulp and seed. The total titratable acidity was higher in the pulp and seeds of green papaya and in the skin of ripe papaya. Higher $\mathrm{pH}$ values were found in the pulp of ripe and overripe papaya, in the seed of the overripe papaya and in the skin of green and overripe papaya. The highest percentage of water was verified in the pulp of green papaya, in the seed of ripe and overripe papaya and in the skin of ripe papaya. The total soluble solids were found at greater amounts in the pulp of overripe papaya, in the seed of ripe and overripe papaya and in the skin of ripe papaya. The Biuret test indicated that the seeds of all papayas contained the highest concentration of protein. The coagulation test was more effective for the pulp of green papaya and the skin of green and overripe papaya, as these parts presented the shortest milk-clotting time, indicating that the enzymes in these parts have a greater ability to break down the protein structures.
\end{abstract}

Key words: Papaya. physical and chemical analysis. postharvest. food safety. quality control. 


\section{INTRODUÇÃO}

O mamoeiro (Carica papaía L.) é originário da América Tropical. As cultivares mais plantadas no Brasil são classificadas nos grupos Formosa, com frutos destinados para o mercado interno, e Solo, com frutos destinados para o mercado interno e para exportação.

Dentre os mais importantes frutos tropicais atualmente cultivados no mundo, o mamão ocupa, evidentemente, um lugar de destaque. O Brasil é o país que mais produz mamão em escala internacional, concentrando $31,6 \%$ da oferta mundial.

Os frutos são organismos vivos e sua vida útil pós-colheita é limitada por reações bioquímicas de natureza catabólica, que culminam com a senescência e morte dos tecidos. Durante o processo de amadurecimento dos frutos, ocorrem inúmeras transformações na sua composição, principalmente, considerando-se a enorme variedade de compostos químicos que elas contêm. As mais importantes são as de significância para o consumidor. No caso do mamão, estas alterações podem ser facilmente identificadas por serem as responsáveis pelas evidentes mudanças na coloração, aroma, sabor e textura destes frutos, que correspondem às principais transformações bioquímicas de interesse comercial, que ocorrem com os pigmentos, compostos voláteis, ácidos orgânicos e carboidratos desses frutos.
O mamão é rico em proteínas, fibras, carboidratos, cálcio, ferro, beta caroteno, vitamina K, ácido ascórbico, tiamina, riboflavia e niacina. As folhas também são nutritivas, sendo grandes fontes de fibras, vitamina $\mathrm{K}$ e de quase todos os componentes do fruto. Folhas frescas de mamão Papaia contém, entre outros, papaína, ácido málico, resina e gordura. As sementes são ricas em óleos graxos, proteínas, óleo volátil, glicosídeo e em fibra.

O destaque vai para a papaína, indicada como excelente para acelerar o processo de digestão. Também é indicada para expulsar vermes intestinais do organismo, pode ser usada no tratamento de verrugas, pomada cicatrizante, amaciante de carnes e para combater as formas mais crônicas de eczema, e de outras irritações que atacam a pele.

O objetivo desse trabalho foi avaliar a qualidade físico-química de mamões comercializados em Campos Gerais, MG, em diferentes estágios de maturação (maduro, verde e de vez) comparando as porções de casca, polpa e semente de cada tipo de mamão.

\section{MATERIAL E MÉTODOS}

\section{Matéria-prima}

Os 36 mamões (Carica papaya L.) foram adquiridos no comércio local de Campos Gerais, MG, e levados para o Laboratório de Análise de Alimentos da 
FACICA, onde foram selecionados em relação ao tamanho, ao estágio de maturação e à ausência de defeitos.

\section{Base metodológica}

O trabalho teve como base metodológica pesquisa científica sobre a caracterização qualitativa e quantitativa das amostras de mamões através de análises físicoquímicas.

\section{Delineamento experimental}

Foi utilizado o delineamento inteiramente casualizado (DIC) sendo os tratamentos arranjados em esquema fatorial (3X3), sendo composto por 3 grupos de mamões em diferentes estágios de maturação (verde, maduro e de vez) e 3 porções de análises (casca, polpa e sementes), com 4 repetições de 3 frutos cada.

\section{Análise estatística}

Os resultados foram submetidos à Análise de Variância, por meio do programa estatístico SISVAR (FERREIRA, 2011). Foi utilizado o teste de Tukey a $5 \%$ de probabilidade.

\section{Preparo das amostras}

Os frutos foram separados, em 3 lotes (verde, maduro e de vez) com 4 repetições de 3 frutos cada, para a realização das análises físico-químicas das porções casca, polpa e semente.
Logo após a separação os frutos foram descascados e separados as porções casca, polpa e sementes. Uma parte foi triturada em homogeneizador de tecidos, na proporção de 1:5 (fruto/água), filtrada em organza para avaliações de $\mathrm{pH}$, sólidos solúveis, acidez titulável e teste do Biureto. O restante das cascas, polpa e sementes foram congeladas e armazenadas em freezer, para análises posteriores.

\section{Análises físico-químicas}

\section{Determinação da umidade \\ O teor de umidade foi realizado} segundo o método gravimétrico da Association of Official Analytical Chemistry - AOAC (2005), que consiste na perda de água por desidratação, em temperaturas de 100 a $105^{\circ} \mathrm{C}$.

\section{Determinação do pH}

$\mathrm{O} \quad \mathrm{pH}$ foi determinado por potênciometria em eletrodo de vidro, utilizando-se um peagâmetro Digital QUIMIS. Segundo técnica da A O A C (2005).

A técnica consistiu em aferir o aparelho com a solução de $\mathrm{pH}$ 7,0 e depois com a solução de pH 4,0. Após cada medida o eletrodo foi lavado com água destilada.

\section{Acidez Total Titulável (ATT)}

A acidez total titulável foi determinada por titulação do filtrado, com uma solução padronizada de $\mathrm{NaOH} \quad 0,1 \mathrm{M}$, segundo a 
técnica da A O A C (2005). Os resultados obtidos foram expressos em $\mathrm{g}$ de ácidos totais por $100 \mathrm{~g}$ de cada porção de mamão.

Para a confecção da solução a ser titulada, foram utilizados $5 \mathrm{~mL}$ do extrato de cada porção (casca, polpa e semente) e completados para $50 \mathrm{~mL}$ com água destilada em erlenmeyer. Logo após foram adicionadas à solução, 3 gotas de corante fenolftaleína a 1\%. A solução foi titulada até o ponto de viragem (cor rosada) e a quantidade gasta de $\mathrm{NaOH}$ foi anotada, para cada amostra.

\section{Sólidos Solúveis Totais (SST)}

A determinação dos sólidos solúveis totais foi determinada com o auxílio de um refratômetro digital de marca Atago, modelo PR-100 Palette, com ajuste automático de temperatura e os resultados foram expressos em porcentagem de sólidos solúveis por $100 \mathrm{~g}$ de cada porção de mamão, conforme metodologia da Association of Official Analytical Chemistry AOAC (2005).

\section{Teste de Biureto}

As soluções aquosas de compostos contendo duas ou mais ligações peptídicas (por exemplo, proteínas) dão origem ao aparecimento de uma cor violeta característica quando tratadas com uma solução diluída de sulfato de cobre em meio alcalino. O nome do teste vem do composto biureto que dá uma reação tipicamente positiva. A cor é devida à formação de um complexo em que o íon cobre se coordena a quatro átomos de azoto das ligações peptídicas. O método do biureto, um dos que se usa para determinar a presença de proteína, tem como base o desenvolvimento de uma cor violeta ou lilás em solução aquosa resultante da reação da proteína com o reagente mencionado (BOBBIO et al., 2003).

Metodologia para determinação de proteína:

Foram colocados em um tubo de ensaio $2 \mathrm{~mL}$ de cada extrato (casca, polpa e semente), $0,5 \mathrm{~mL}$ de sulfato de cobre $\left(\mathrm{CuSO}_{4}\right) \quad 1 \%$ e 0,5mL de hidróxido de sódio $(\mathrm{NaOH}) 10 \%$. Foi agitado e observado o aparecimento de uma coloração lilás ou violeta.

\section{Coagulação do leite}

Através deste teste é calculada a potência da enzima em quebrar a estrutura de proteínas do leite (substrato). Em este método $10 \mathrm{mg}$ de cada porção (casca, polpa e semente) a uma concentração de $1 \mathrm{~g}$ de amostra em $10 \mathrm{~g}$ de ácido acético $(0,01 \%)$ será adicionado a uma solução de $10 \mathrm{~mL}$ de leite $(2,5 \mathrm{~g}$ de leite em pó em $100 \mathrm{~g}$ de água) a qual foi aquecida em banho a $50^{\circ} \mathrm{C}$. O conteúdo do tubo foi agitado até o primeiro sinal de formação de coágulos. O tempo que demorou na formação do coágulo foi registrado e comparado com as demais amostras (MING et al., 2002). 


\section{RESULTADOS E DISCUSSÃO}

\section{Análises físico-químicas}

\section{Acidez total titulável (ATT)}

O teor de acidez do mamão é relativamente baixo, o que contribui para que o seu $\mathrm{pH}$ seja moderadamente alto, em media 5,5 a 5,9 (FOLEGATTI, MATSURRA, 2002).

TABELA 1 - Teores médios de acidez total titulável $\left(\mathrm{NaOH}\right.$ 0,1M. $\left.100 \mathrm{~g}^{-1}\right)$ em mamões em diferentes estágios de maturação.

\begin{tabular}{ccccc}
\hline $\begin{array}{c}\text { Tratamento } \\
\text { / porções }\end{array}$ & Polpa & Semente & Casca & CV \\
\hline Maduro & $0,82 \mathrm{Aa}$ & $1,15 \mathrm{Bb}$ & $2,93 \mathrm{Cc}$ & \\
De vez & $0,74 \mathrm{Aa}$ & $0,92 \mathrm{Aa}$ & $2,07 \mathrm{Ac}$ & $6,06 \%$ \\
Verde & $1,1 \mathrm{Ba}$ & $2,19 \mathrm{Cb}$ & $2,32 \mathrm{Bb}$ & \\
\hline
\end{tabular}

* Médias seguidas por letras distintas minúsculas nas linhas e maiúsculas nas colunas diferem entre si, pelo teste de Tukey, a 5\% de probabilidade.

FONTE - Laboratório de Química - FACICA 2015.

De acordo com os resultados observados na Tabela1, estatisticamente, a casca do mamão maduro teve maior acidez (2,93 NaOH 0,1M. $\left.100 \mathrm{~g}^{-1}\right)$ seguida da semente $\left(1,15 \mathrm{NaOH}\right.$ 0,1M. $\left.100 \mathrm{~g}^{-1}\right)$ e a porção que obteve os menores valores foi a polpa $(0,82$ $\mathrm{NaOH}$ 0,1M. $100 \mathrm{~g}^{-1}$ ). No mamão de vez a casca foi a porção que apresentou os maiores valores de acidez (2,07 $\left.\mathrm{NaOH} 0,1 \mathrm{M} .100 \mathrm{~g}^{-1}\right)$ seguida da semente $\left(0,92 \mathrm{NaOH} 0,1 \mathrm{M} .100 \mathrm{~g}^{-1}\right)$ e da polpa $\left(0,74 \mathrm{NaOH} 0,1 \mathrm{M} .100 \mathrm{~g}^{-1}\right)$ que não obtiveram diferenças estatísticas. No mamão verde a casca e a semente foram as porções que apresentaram os maiores teores de acidez
(2,32 NaOH 0,1M. $100 \mathrm{~g}^{-1}$ e 2,19 NaOH 0,1M. $100 \mathrm{~g}^{-1}$ respectivamente) seguidas da polpa que obteve os menores teores $(1,1 \mathrm{NaOH} 0,1 \mathrm{M}$. $\left.100 \mathrm{~g}^{-1}\right)$.

Os teores de acidez deste trabalho foram superiores aos mencionados por Alves et al., (2003) quando estudavam a cultura do mamoeiro e as tecnologias de produção. Esta diferença nos teores de acidez pode ser devido a diferentes cultivares, parte do fruto analisada, grau de maduração, tipo de plantio dentre outros fatores.

\section{Determinação de pH}

As alterações nos valores do $\mathrm{pH}$ dos frutos resultam da produção de ácidos orgânicos ao longo do amadurecimento póscolheita (PAIVA et al., 2009). Chan Junior et al (1971) apud Junior et al (2007) mencionou que o mamão apresenta o $\mathrm{pH}$ entre 4,5 e 6,0 baseando nisto, pode se dizer que os frutos analisados neste trabalho apresentam $\mathrm{pH}$ no intervalo considerado ideal para ser consumido in natura.

TABELA 2 - Valores médios de pH em mamões em diferentes estágios de maturação.

\begin{tabular}{ccccc}
\hline $\begin{array}{c}\text { Tratamento } \\
\text { / Porções }\end{array}$ & Polpa & Semente & Casca & CV \\
\hline Maduro & $5,78 \mathrm{Bc}$ & $5,68 \mathrm{Aa}$ & $5,53 \mathrm{Aa}$ & \\
De vez & $5,78 \mathrm{Ba}$ & $5,85 \mathrm{Cb}$ & $5,97 \mathrm{Bc}$ & $0,45 \%$ \\
Verde & $5,71 \mathrm{Aa}$ & $5,79 \mathrm{Bb}$ & $5,99 \mathrm{Bc}$ & \\
\hline
\end{tabular}

* Médias seguidas por letras distintas minúsculas nas linhas e maiúsculas nas colunas diferem entre si, pelo teste de Tukey, a 5\% de probabilidade.

FONTE - Laboratório de Química - FACICA 2015. 
De acordo com os resultados da Tabela 2 , estatisticamente, a polpa do mamão maduro teve o maior valor de $\mathrm{pH}(5,78)$ seguida da semente $(5,68)$ e a da casca $(5,53)$ que não tiveram diferenças estatísticas. No mamão de vez a casca foi a porção que apresentou os maiores valores de $\mathrm{pH}(5,97)$ seguida da semente $(5,85)$ e a porção que obteve os menores valores foi a polpa $(5,78)$. No mamão verde a casca foi à porção que apresentou os maiores valores $(5,99)$ seguida da semente $(5,79)$ e a porção que obteve os menores valores foi a polpa $(5,71)$.

Fioravanço et al., (1994) estudando a qualidade do mamão Papaya comercializado em Porto Alegre, encontraram valores de $\mathrm{pH}$ em torno de 5,28 a 5,86 valores semelhantes aos encontrados neste trabalho que foram de 5,53 a 5,99 .

De acordo com Chan Júnior et al., (1971) o mamão apresenta um $\mathrm{pH}$ entre 4,5 e 6,0 baseado nisto, pode-se dizer que os frutos comercializados em Campos Gerais, MG, apresentaram valores de $\mathrm{pH}$ no intervalo considerado ideal para o consumo in natura.

\section{Determinação da umidade}

A presença de umidade determina a efetiva possibilidade que a água tem de promover a ocorrência de reações químicas, enzimáticas e microbiológicas no alimento (GONÇALVES e BLUME, 2008). O alimento desidratado apresenta um percentual mínimo de umidade, chamada de umidade residual, que é normal e desejável ao produto (CRUZ,
1989). A umidade residual tem influência na consistência do produto. Quanto maior for esta umidade, mais macia será a consistência do produto final.

TABELA 3 - \% de umidade em mamões em diferentes estágios de maturação.

\begin{tabular}{ccccc}
\hline $\begin{array}{c}\text { Tratamento } \\
\text { / Porções }\end{array}$ & Polpa & Semente & Casca & CV \\
\hline Maduro & $12,52 \mathrm{Aa}$ & $18,54 \mathrm{Bc}$ & $16,50 \mathrm{Cb}$ & \\
De vez & $13,06 \mathrm{Aa}$ & $17,64 \mathrm{Bc}$ & $13,96 \mathrm{Bb}$ & $3,64 \%$ \\
Verde & $13,74 \mathrm{Bc}$ & $10,38 \mathrm{Aa}$ & $12,68 \mathrm{Ab}$ & \\
\hline
\end{tabular}

* Médias seguidas por letras distintas minúsculas nas linhas e maiúsculas nas colunas diferem entre si, pelo teste de Tukey, a 5\% de probabilidade.

FONTE - Laboratório de Química - FACICA 2015.

De acordo com os resultados da Tabela 3, estatisticamente, a semente do mamão maduro teve maior teor de umidade $(18,54 \%)$ seguida da casca $(16,50 \%)$ e a da polpa $(12,52 \%)$. No mamão de vez a semente foi à porção que apresentou os maiores valores de umidade $(17,64 \%)$ seguida da casca $(13,96 \%)$ e a porção que obteve os menores valores foi a polpa $(13,06 \%)$. No mamão verde a polpa foi à porção que apresentou os maiores valores $(13,74 \%)$ seguida da casca $(12,68 \%)$ e a porção que obteve os menores valores foi a semente $(10,38 \%)$.

Em estudos com mamão, Ramos (2008) observou que com a redução da umidade ocorreu também uma diminuição da maciez do produto, acarretando um produto crocante e de difícil mastigação. 


\section{Sólidos solúveis totais}

Os sólidos solúveis totais indicam a quantidade de açúcar existente no mamão. Um dos fatores que pode afetar o teor de sólidos solúveis nos frutos é a taxa respiratória, pois os açúcares constituem um dos substratos para a respiração (PIMENTEL et al., 2011).

TABELA 4 - Teores médios de sólidos solúveis totais (\%) em mamões em diferentes estágios maturação.

\begin{tabular}{ccccc}
\hline $\begin{array}{c}\text { Tratamento } \\
/\end{array}$ & Polpa & Semente & Casca & CV \\
Porções & & & & \\
\hline Maduro & $6,6 \mathrm{Bb}$ & $4,8 \mathrm{Ba}$ & $6,6 \mathrm{Cb}$ & \\
De vez & $9,6 \mathrm{Cc}$ & $4,8 \mathrm{Ba}$ & $4,2 \mathrm{Ba}$ & $4,33 \%$ \\
Verde & $6,0 \mathrm{Ac}$ & $1,8 \mathrm{Aa}$ & $3,6 \mathrm{Ab}$ & \\
\hline
\end{tabular}

* Médias seguidas por letras distintas minúsculas nas linhas e maiúsculas nas colunas diferem entre si, pelo teste de Tukey, a 5\% de probabilidade.

FONTE - Laboratório de Química - FACICA 2015.

Observando os resultados da Tabela 4, estatisticamente, a polpa e a casca do mamão maduro obtiveram os maiores valores de sólidos solúveis $(6,6 \%)$ seguidos da semente que teve teor médio de $4,8 \%$. No mamão de vez a polpa foi à porção que apresentou os maiores valores de sólidos solúveis $(9,6 \%)$ seguida da semente e da casca $(4,8 \%$ e $4,2 \%$ respectivamente), que não apresentaram diferenças estatisticamente. No mamão verde a polpa foi à porção que apresentou os maiores valores $(6,0 \%)$ seguida da casca $(3,6 \%)$ e a porção que obteve os menores valores foi à semente $(1,8 \%)$.

Gomes et al., (2002) não encontraram diferenças significativas nos teores de açúcares solúveis em mamões verdes, de vez e maduro. Sugeriram que a percepção do sabor doce pode estar relacionada ao desaparecimento do látex, devido a mudanças nos níveis de compostos fenólicos, considerado uma característica de fruto verde pelos julgamentos de analise sensorial.

\section{Teste do Biureto}

$\mathrm{O}$ teste do Biureto foi realizado utilizando uma solução diluída de sulfato de cobre, em meio alcalino que dá-se origem a uma coloração violeta, que determina a concentração de proteína, quanto mais escuro maior a concentração de proteína.

TABELA 5 - Teste do Biureto realizado em amostras de mamões em diferentes estágios de maturação.

\begin{tabular}{|c|c|c|c|}
\hline $\begin{array}{l}\text { Tratamento / } \\
\text { Porções }\end{array}$ & Polpa & Semente & Casca \\
\hline Maduro & $\begin{array}{l}\text { Verde } \\
\text { claro }\end{array}$ & $\begin{array}{l}\text { Cinza } \\
\text { escuro }\end{array}$ & $\begin{array}{l}\text { Verde } \\
\text { claro }\end{array}$ \\
\hline De vez & $\begin{array}{l}\text { Verde } \\
\text { claro }\end{array}$ & $\begin{array}{l}\text { Cinza } \\
\text { escuro }\end{array}$ & $\begin{array}{l}\text { Verde } \\
\text { escuro }\end{array}$ \\
\hline Verde & $\begin{array}{l}\text { Lilás } \\
\text { claro }\end{array}$ & $\begin{array}{l}\text { Cinza } \\
\text { escuro }\end{array}$ & $\begin{array}{l}\text { Verde } \\
\text { escuro }\end{array}$ \\
\hline
\end{tabular}

FONTE - Laboratório de Química - FACICA 2015.

Observando a Tabela 5 pode-se concluir que no mamão maduro a semente obteve maior concentração de proteína (cinza escuro) seguida da polpa e da casca, que não tiveram diferença de cor (verde claro). No mamão de vez pode-se observar que a semente foi à porção que obteve a maior concentração de proteína devida a cor cinza escuro seguida da casca que apresentou a cor verde escuro e a porção que obteve o menor teor de proteína foi a polpa (verde claro). No mamão verde a semente obteve o maior teor de proteína (cinza escuro) seguida da casca (verde escuro) e a 
que obteve o menor teor foi à polpa (lilás claro).

Bobbio (2003) não encontra diferenças no teste do biureto pois, a reação com o biureto confirma a presença de aminoácidos e proteínas, o reagente de biureto reage com ligações peptídicas em polipeptídeos tanto na enzima obtida quanto na enzima comercial.

\section{Coagulação do leite}

O teste de coagulação do leite é utilizado para calcular a capacidade da enzima em quebrar a estrutura da proteína do leite, quanto maior o tempo menor a capacidade da enzima em quebrar a estrutura da proteína.

TABELA 6 - Tempo (minuto) de coagulação do leite realizado em amostras de mamões em diferentes estágios de maturação.

\begin{tabular}{cccc}
\hline $\begin{array}{c}\text { Tratamento } \\
\text { / Porções }\end{array}$ & Polpa & Semente & Casca \\
\hline Maduro & 9,0 & 8,0 & 12,0 \\
De vez & 3,0 & 2,0 & 1,0 \\
Verde & 1,0 & 2,0 & 1,0 \\
\hline
\end{tabular}

FONTE - Laboratório de Química - FACICA 2015.

De acordo com a Tabela 6 pode-se concluir que no mamão maduro a semente foi à porção que obteve menor tempo (8,0 min.) seguida da polpa $(9,0 \mathrm{~min}$.) e a porção que teve o maior tempo foi à casca $(12,0$ min. $)$. No mamão de vez a casca foi à porção que obteve o menor tempo (1,0 min.) seguida da semente (2,0 min.) e a porção que teve o maior tempo foi a polpa (3,0 min.). No mamão verde a polpa e a casca foram as que tiveram o menor tempo (1,0 min.) seguidas da semente $(2,0$ min.).

Fazendo estudos com mamão, Ming et al., (2002) obteve basicamente a mesma variação de tempo em minutos, referente ao tempo de coagulação do mamão. Obtendo apenas uma diferença em relação à casca, a polpa e a semente do mamão maduro, que foram apresentados da seguinte forma, polpa 4 , semente 5 e casca 6 minutos.

\section{CONCLUSÃO}

A acidez total titulável foi maior na polpa e semente do mamão verde e na casca do mamão maduro;

Os maiores valores de $\mathrm{pH}$ foram encontrados nas polpas dos mamões maduro e de vez, na semente do mamão de vez e na casca do mamão de vez e verde;

Os maiores percentuais de água foram determinados na polpa do mamão verde, nas sementes dos mamões maduro e de vez e na casca do mamão maduro.

Os teores de sólidos solúveis totais foram encontrados em maior quantidade na polpa do mamão de vez, nas sementes dos mamões maduro e de vez e na casca do mamão maduro.

Com o teste do Biureto pode-se concluir que as sementes de todos os mamões analisados foram às porções que apresentaram maior concentração de proteínas.

O teste de coagulação foi mais eficiente na polpa do mamão verde e nas cascas dos 
mamões de vez e verde, pois foram as porções que apresentaram o menor tempo de coagulação do leite, demonstrando que as enzimas presentes nestas porções possuem

\section{REFERÊNCIAS BIBLIOGRÁFICAS}

ALVES, F.L.; BALBINO, J.M.S.;

BARRETO, F.C. A cultura do mamoeiro:

tecnologias de produção, 1.ed. Vitória, Incaper, 2003. 497p.

\section{ASSOCIATION OF OFFICIAL}

ANALYTICAL CHEMISTRY. Official

methods of analysis of the association of

official agriculture chemistry. 18. ed.

Mayland: AOAC, 2005. 1094 p.

BOBBIO F. O.; BOBBIO. P. A. Introdução à química de alimentos. 3 ed. São Paulo : Varela, 2003. 238p.

CHAN JR., H.T. et al. Nonvolatile acids of papaya. J. Agr. Food Chem., n.19, p.263265. 1971.

CRUZ, G.A. Desidratação de Alimentos. 2 ed., São Paulo, Editora Globo, 1989. 207p.

FERREIRA, D. F. Sisvar: a computer statistical analysis system. Ciência e Agrotecnologia, v. 35, n. 6, p. 1039-1042, 2011. maior capacidade de quebrar as estruturas proteicas.

FIORAVANÇO, J.C.; PAIVA, M.C.;

CARVALHO, R.I.N. de.; MANICA, I.

Características do mamão Formosa

comercializado em Porto Alegre de outubro/91 junho/92. Ciência Rural, Santa Maria, v.24, n.3, p.519-522, 1994.

FOLEGATTI, M. I. S.; MATSUURA, F. C. A. U. Produtos. In: FOLEGATTI, M. I. S.; MATSUURA, F. C. A. U. Mamão: Póscolheita. Brasília, Distrito Federal: Embrapa Informação Tecnológica, 2002. p. 50-55. (Série Frutas do Brasil, 21).

GOMES, P. M. de A., FIGUEIRÊDO, R. M. F., QUEIROZ, A. J. de. Caracterização e isotermas de adsorção de umidade da polpa de acerola em pó. Revista Brasileira de Produtos Agroindustriais, Campina Grande, v.4, n.2, p.157-165, 2002.

GONÇALVES, A. A.; BLUME, A. R. Efeito da desidratação osmótica como tratamento preliminar na secagem do abacaxi. Estudos Tecnológicos. v. 4, n. 2, p. 124-134, 2008.

JÚNIOR, F. R.; TORRES, L. B. V.;

CAMPOS, V. B.; LIMA, A. R.; OLIVEIRA, 
A. D.; MOTA, J. K. M. Caracterização físicoquímica de frutos de mamoeiro

comercializados na Empasa de Campina Grande-PB. Revista Brasileira de Produtos Agroindustriais, v. 9, n. 1, p. 53-58, 2007.

MING, C. C.; BONO, A.; KRISHNAIAH, D.; e HAN, T. S. 2002. Effects ionic and non-ionic surfactants on papain activity.

Borneo Sci. v. 12, p. 71 - 77, 2002.

PAIVA, G.; SANTOS, K. A.; ZACCA, P. L. Análises físico-químicas de mamão (Carica papaya L.) em diferentes estágios de maturação. In: IV SIMPÓSIO DO PAPAYA BRASILEIRO, 4., 2009. Vitória, Espírito Santo.
PIMENTEL, J. D. R.; SOUZA, D. S.; OLIVEIRA, T. V.; OLIVEIRA, M. C.; BASTOS, V. S.; CASTRO, A. A. Estudo da conservação de mamão Havaí utilizando películas comestíveis a diferentes temperaturas. Scientia Plena. v 7, n. 10, p. 16, 2011.

RAMOS, A.M.; QUINTERO, A.C.F.; FARAONI, A.S.; SOARES, N.F.F.; PEREIRA, J.A.M. Efeito do tipo de embalagem e do tempo de armazenamento nas qualidades físico-química e microbiológica de abacaxi desidratado. Alimentos e Nutrição. v.19, n.3, p. 259-269, jul./set. 2008. 